\title{
Les Jornades de Controvèrsia Sòcio-Científica i Recerca i Innovació Responsables: Ciències per a qüestionar i canviar el món. Pensar, comprendre, decidir.
}

Jordi Domènech-Casal (jdomen44@xtec.cat) Grup LIEC, Departament de Didàctica de les Matemàtiques $i$ les Ciències Experimentals, Universitat Autònoma de Barcelona; i Servei d'Immersió i Acollida Lingüística, Departament d'Ensenyament de la Generalitat de Catalunya.

Sílvia Lope (slope@xtec.cat) Centre de Recursos Pedagògics Específics de Suport a la Innovació i la Recerca Educativa (CESIRE).

Les controvèrsies sòcio-científiques $i$ la recerca $i$ innovació responsables constitueixen enfocs educatius clau per a la formació d'una ciutadania crítica i contexts rellevants per a l'ensenyament de les Ciències. Amb l'objectiu de facilitar $i$ promoure el treball amb aquests enfocs, s'han organitzat $i$ dut a terme unes Jornades amb la participació de diversos agents educatius. Es presenten i justifiquen breument les jornades així com els materials que n'han resultat.

Paraules clau: Controvèrsies, RRI, Jornades, Recursos didàctics.

Socio-Scientific Issues (SSI) and Responsible Research and Innovation (RRI) are key educational approaches for educating Critical Citizenship, and constitute relevant context for Science Education. To promote the use of such approaches in school Science Education, we have organized and developed a Seminar on the topics, with the participation of several Science Education stakeholders. In this article, we present and justify briefly the Seminar and the resulting materials.

Keywords: Socio-Scientific Issues, RRI, Seminar, Educational Resources.

\section{INTRODUCCIÓ}

L'ensenyament de les ciències, més enllà del domini dels models científics ha de promoure que els alumnes siguin capaços de transferir-los a nous contexts (Hodson, 1994), adquireixin habilitats científiques i una visió crítica del món que els envolta (Solbes, 2013), que els capaciti per a prendre decisions en contexts de la vida real participats per models científics (OCDE, 2013).

Les controvèrsies sòcio-científiques (CSC en endavant) son qüestions 0 dilemes socialment rellevants amb vincles conceptuals amb la ciències i que tenen una resposta oberta i complexa
(España i Prieto, 2010). Constitueixen bons escenaris per al treball de les ciències en context, i ubiquen els conceptes i models científics en situacions de conflicte que promouen un aprenentatge més profund (Sanmartí et al, 1999, Sadler, 2011).

A més, el treball amb CSC permet ensenyar l'alumnat a prendre decisions en situacions participades per models científics, però també per valors personals o components ètiques o socials, i promou el treball específic d'habilitats cognitivolingüístiques (descriure, justificar, argumentar) en formats comunicatius (debat, assaig) de construcció del coneixement científic, preparant els 
alumnes per aprendre ciència al llarg de la vida (Díaz y Jiménez-Liso, 2012) i reconèixer-la en el dia a dia.

Aquesta dimensió d'Alfabetitizació Científica de les Controvèrsies sòcio-científiques s'ha accentuat els darrers anys més enllà de la Ciutadania Crítica amb la definició d'una nova aproximació a les relacions entre Ciència i Societat, la Recerca i i Innovació Responsables (RRI en les seves inicials en anglès).

La RRI propugna l'empoderament de la ciutadania no només com a destinatari final de la ciència (Ciència per a la societat), sinó com a participant actiu en la recerca des de les seves etapes inicials (Ciència amb la Societat), amb l'objectiu d'alinear la recerca científica amb els valors de la societat.

Primeres iniciatives en aquest sentit, com la Ciència Ciutadana (en la que els ciutadans participen en primera persona com a investigadors) o els Science Cafés (on s'estableixen converses informals d'intercanvi de visions i opinions entre ciutadans i investigadors) (Domènech-Casal, 2014a) han anat obrint pas a plans institucionals de major envergadura amb suport d'institucions polítiques com la Comissió Europea. Es pot dir que les demandes socials van avui més enllà d'un model de ciutadà que és capaç de pensar científicament i demanden un model de ciutadà que pensa científicament per a actuar com a ciutadà $i$ que les demandes educatives en ensenyament de les ciències demanen connectar els marcs metodològics (indagació, treballs pràctics, noves tecnologies) amb controvèrsies rellevants (Domènech-Casal, 2014b). I aquestes demandes connecten amb propostes metodològiques ja conegudes (com l'aprenentatge-servei, o APS) i noves propostes, com l'Educació Pel Desenvolupament, o EDP.

\section{Perquè unes Jornades sobre CSC $\mathbf{i}$ RRI}

Tot que els enfocs pedagògics dels treball amb CSC i RRI es corresponen amb les mencions expresses en el currículum de la necessitat de connectar els models científics amb contexts socialment rellevants (Sadler i Zeidler, 2009), aquests enfocs són poc usats a les aules i perviuen les pràctiques reproductives on el context no juga un paper rellevant (Gilbert, 2006).

Les raons d'aquesta absència són diverses, i engloben aspectes didàctics (com desenvolupar, aplicar i avaluar seqüències didàctiques CSC 0
RRI), pedagògics (quin és el paper educador de l'escola) i de recursos (on i com trobar recursos per a dur a terme aquestes activitats).

L'emergència de les Pseudociències, els reptes d'un món Globalitzat i Industrialitzat, la Tecnificació de les relacions socials i els rapidíssims avenços científics amb possibles conseqüències en la vida de les persones o equilibris socials i econòmics (transgènics, vacunes, nanotecnologia,...) demanen un cop de timó en aquesta tendència a l'ensenyament descontextualitzat de les ciències.

\section{LES JORNADES: UNA CONFLUÈNCIA D'ACTORS EN L'AMMBIT}

En aquest marc, s'han dut a terme les Jornades de Controvèrsies Sòcio-Científiques i Recerca i Innovació Responsables, per ajudar i orientar el professorat en el treball amb aquests enfocs. En les ponències, experts de diferents àmbits (professors de secundària, directors de projectes europeus en RRI, professors universitaris, experts en didàctica) han ofert la seva mirada sobre el treball amb CSC i RRI a l'aula, amb el lema general: Ciències per a qüestionar i canviar el món. Pensar, comprendre, decidir.

El programa, els títols de les ponències i les presentacions de diapositives s'han ofert al blog de les Jornades [1], i els resums de les ponències s'han organitzat en tres articles que ofereix la revista Ciències en aquest número:

- Experiències d'aula amb el treball amb Controvèrsies Sòcio-Científiques. Educació per al Desenvolupament i la Salut, Pseudociències i eines per a l'avaluació d'activitats (DomènechCasal, Marchán i Vergara, 2015).

- Les Controvèrsies Sòcio-Científiques com a contextos d'aprenentatge i comunicació a l'aula. Anàlisi crítica de la informació i habilitats comunicatives (Farró et al, 2015).

- Els projectes Europeus Engaging Science, Xplore Health, RRI Tools i Scientix. Finestres a la formació i la participació en comunitats docents per al treball amb Controvèrsies i Recerca i Innovació Responsables (AlcarazDomínguez et al, 2015).

Tant el blog de les Jornades com la publicació d'aquests articles tenen per objectiu donar el màxim abast possible als materials presentats $i$ mantenir-los com a recurs permanent per al professorat interessat en el treball amb CSC i RRI a l'aula. 


\section{AGRAIIMENTS}

Aquest article presenta les ponències presentades a les "Jornades de Controvèrsia Sòcio-Científica i Recerca i Innovació Responsables. Ciències per a qüestionar i canviar el món. Pensar, comprendre, decidir." [1], que es van celebrar els dies 21-X, 4-XI i 25 XI de 2015 al CESIRE de Barcelona (Drassanes) del Departament d'Ensenyament de la Generalitat de Catalunya, i es recullen en forma d'articles en aquest mateix número de la revista Ciències.

Els organitzadors de les Jornades (Sílvia Lope i Jordi Domènech), agraïm la participació dels diversos ponents i la col-laboració del CESIRE de Barcelona, el Servei d'Acollida i Immersió Lingüística del Departament d'Ensenyament.

\section{BIBLIOGRAFIA}

ALCARAZ-DOMÍNGUEZ, S., BARAJAS, M., MALAGRIDA, R., PÉREZ, F. (2015). Els projectes Europeus Engaging Science, Xplore Health, RRI Tools $i$ Scientix. Finestres a la formació i la participació en comunitats docents per al treball amb Controvèrsies i Recerca $i$ Innovació Responsables. Revista Ciències, 30, 47-54.

DÍAZ, N., JIMÉNEZ-LISO, M. R. (2012). Las controversias sociocientíficas: temáticas $e$ importancia para la educación científica. Revista Eureka sobre Enseñanza y Divulgación de las Ciencias 9(1), 54-70.

DOMĖNECH-CASAL, J. (2014a). Indagación en el aula mediante actividades manipulativas $y$ mediadas por ordenador. Alambique, Didáctica de las Ciencias Experimentales 76, 17-27.

DOMĖNECH-CASAL, J. (2014b). Contextos de indagación y controversias socio-científicas para la enseñanza del Cambio Climático. Enseñanza de las Ciencias de la Tierra 22(3), 267-276.

DOMĖNECH-CASAL, J., MARCHÁN, I., VERGARA, E. (2015). Experiències d'aula amb el treball amb Controvèrsies Sòcio-Científiques. Educació per al Desenvolupament i la Salut,
Pseudociències $i$ eines per a l'avaluació d'activitats. Revista Ciències, 30, 32-38.

ESPAÑA, E., PRIETO, T. (2010). Problemas sociocientíficos y enseñanza-aprendizaje de las ciencias. Investigación en la escuela, 71, 17-24.

FARRÓ, L., LOPE, S., MARBÀ, A., OLIVERAS, B. (2015). Les Controvèrsies Sòcio-Científiques com a contextos d'aprenentatge i comunicació a l'aula. Anàlisi crítica de la informació $i$ habilitats comunicatives. Revista Ciències, 30, 39-46.

GILBERT, J.K. (2006). On the nature of "context" in chemical education. International Journal of Science Education, 28(9), 957-976.

HODSON, D. (1994). Hacia un enfoque más crítico del trabajo de laboratorio. Enseñanza de las Ciencias, 12(3), 299-313.

OCDE (2013). PISA 2015. Draft Science Framework.

[http://www.oecd.org/pisa/pisaproducts/Draft PISA 2015 Science Framework .pdf] Consultado 15/03/2015.

SADLER, T. D. (2011). Situating Socio-scientific Issues in Classrooms as a Means of Achieving Goals of Science Education, en Sadler, T. D. (Ed.) Socio-scientific Issues in the Classroom: Teaching, learning and research (pp. 1-9). Netherlands: Springer.

SADLER, T.D., ZEIDLER, D.L. (2009). Scientific literacy, PISA and socio-scientific discourse: Assessment for progressive aims of science education. Journal of Research in Science Teaching, 46 (8), 909-921.

SANMARTII, N; IZQUIERDO, M; GARCÍA, P. (1999) Hablar y escribir: una condición para aprender ciencia. Cuadernos de Pedagogía, 281, 54-58.

SOLBES, J. (2013). Contribución de las cuestiones sociocientíficas al desarrollo de pensamiento crítico (I): Introducción. Revista Eureka sobre Enseñanza y Divulgación de las Ciencias, 10 (1), 1-10.

[1] Blog de les Jornades de Controvèrsies SòcioCientífiques i Recerca i Innovació Responsables disponible a:

https://cienciaicontroversia.wordpress.com/ 